\title{
“Del qual tenim LOCH”. LeONOR DE Sicilia y EL ORIGEN DE LA LUGARTENENCIA FEMENINA EN LA Corona de Aragón ${ }^{1}$
}

Lledó Ruiz Domingo²

Universitat de València

\section{Resumen}

Durante la Baja Edad Media algunas reinas consortes de la Corona de Aragón ejercieron la Lugartenencia real, un cargo gubernamental por el cual ocupaban la posición propia de su marido, convirtiéndose en su alter ego. En el presente artículo pretendemos esclarecer los detalles de la primera Lugartenencia ejercida por una reina en la Corona de Aragón, dilucidar los motivos de su elección y la importancia que tendría para los posteriores monarcas.

\section{Palabras clave}

Reina; Reginalidad; Corona de Aragón; Lugartenencia; Leonor de Sicilia.

\begin{abstract}
During the Late Middle Ages some queens consort of the Crown of Aragon were designated as lieutenants. Lieutenancy was a governmental office in which the king delegated all his power during a period of absence. In the present article we intend to clarify the details of the first Lieutenancy exercised by a queen in the Crown of Aragon and to explain the reasons for her election and its importance for the following monarchs.
\end{abstract}

\section{Key Words}

Queens; Queenship; Crown of Aragon; Lieutenancy; Eleanor of Sicily.

\section{Resumo}

Durante o final da Idade Média algumas rainhas consortes da Coroa de Aragão foram designadas como lugartenientes. A Tenência era um cargo governamental em que o rei delegou todo seu poder durante um período de ausência. No presente artigo pretendemos esclarecer os pormenores da primeira tenência exercida por uma rainha na Coroa de Aragão e explicar as razões da sua eleição ea importância para os monarcas posteriores.

\section{Palavras-chave}

Rainha; Reginalidade; Coroa de Aragão; Lugartenencia; Leonor de Sicília.

1 Este artículo se inserta en el marco del proyecto de investigación Crecimiento económico y desigualdad social en la Europa Mediterránea (siglos XIII-XV), HAR2014-588730-P, financiado por el Ministerio de Economía, Industria y Competitividad del Gobierno de España.

2 Becaria de investigación de la Universitat de València bajo el programa de contratos pre-doctorales Atracció De Talent. Correo electrónico: lledo.ruiz.domingo@gmail.com. 


\section{Introducción}

Tal y como señala S. Péquignot, la historia política, aun siendo un tema de investigación clásico, está protagonizando, en la actualidad, una revitalización historiográfica ${ }^{3}$. Las nuevas aproximaciones han buscado procurar una visión más transversal y en profundidad de la monarquía, para lo cual, por un lado, se han reconsiderado las relaciones de ésta con aquellos que integraban la corte, con el territorio sobre el que gobernaban, con los otros poderes en relación, con los mecanismos de construcción de entidades políticas públicas, entre otros; y por otro, se ha vuelto a examinar la institución monárquica en sí misma, incluyendo como sujetos de estudio las reinas consortes y los infantes, especialmente el primogénito, para así comprender la articulación interna de la institución a la cabeza de la política y del gobierno medievales ${ }^{4}$.

Por lo que respeta a las reinas consortes, hasta los años sesenta del siglo XX los trabajos sobre ellas no iban más allá de estudios concretos, muchos de ellos biográficos ${ }^{5}$. Sin embargo, las perspectivas de análisis de la historia de las mujeres sufrieron un revulsivo en los años ochenta cuando, impulsadas por los cambios en otras disciplinas de la historia, consiguieron integrar a las mujeres como sujetos historiográficos incluso

\footnotetext{
Stéphane PÉQuignot, "Pouvoir royal et sociétés dans la couronne d'Aragon: un essai de lectura historiographique (1990-2006)", En la España medieval, 30 (2007), pp. 381-432. En este trabajo encontramos una extensa relación de toda la bibliografía publicada acerca de la historia política y sus diferentes vertientes en las décadas previas a su escritura.

4 Se recoge un repaso en profundidad de la evolución historiográfica de la reina consorte como sujeto de estudio en: Diana Pelaz Flores y Ma Isabel del Val Valdivieso, "La Historia de las Mujeres en el siglo XXI a través del estudio de la Reginalidad medieval", Revista de Historiografia, 22 (2015), pp. 101-127; $\mathrm{M}^{\mathrm{a}}$ Isabel del VAL VALDIVIESo, "La historia de las mujeres medievales en España", Ser mujer en la ciudad medieval europea, Beatriz Arízaga Bolumburu, Jesús Ángel Solórzano Telechea y Amélia Aguiar Andrade (eds.), ed. Instituto de Estudio Riojanos, Logroño 2013, pp. 19-38; Ana EchEVARRía y Nikolas JASPERT, "Introducción: el ejercicio del poder de las reinas ibérica en la Edad Media", Anuario de Estudios medievales, 46 (2016), pp. 3-33. También es importante señalar trabajos sobre la relevancia del primogénito dentro de la monarquía, por ejemplo: José María de Francisco Olmos, El príncipe heredero en las Coronas de Castilla y Aragón durante la Baja Edad Media, Universidad Complutense de Madrid, 2004, Tesis Doctoral.

5 Josep Maria RocA, "La Reyna empordanesa", Memorias de la Real Academia de Buenas Letras de Barcelona, 10 (1928), pp. 2-211; Ferran Soldevila, "La Reyna Maria, muller del Magnànim", Memorias de la Real Academia de Buenas Letras de Barcelona, 10 (1928), pp. 213-347; Ulla DeIBEL, "La Reyna Elionor de Sicilia", Memorias de la Real Academia de Buenas Letras de Barcelona, 10 (1928), pp. 349-453; Aurea Javierre Mur, María de Luna, reina de Aragón, ed. Consejo Superior de Investigaciones Científicas, Instituto Jerónimo Zurita, Madrid, 1942; Francisco Martínez Martínez, "Una visita al cenobio de la Santísima Trinidad, de Valencia, sepultura de la reina doña María", Anales del Centro de Cultura Valenciana, 13 (1945), pp. 167-185; Núria Coll Julí,, Doña Juana Enríquez, lugarteniente real en Cataluña (1461-1468), ed. Consejo Superior de Investigaciones Científicas, Biblioteca Reyes Católicos, Madrid, 1953; Francisca Hernández-León de Sánchez, Doña María de Castilla, esposa de Alfonso V el Magnánimo, ed. Facultad de Filosofía y Letras, Valencia, 1959; Alberto Boscolo, La reina Sibil la de Fortià, ed. Rafael Dalmau, Barcelona, 1970; Francesc A. Miquel, "La reina Blanca d'Anjou", Episodis de la Historia, 197 (1975); Eufemià Fort Cogul, "Precisions sobre la data en què morí la reina Blanca d'Anjou", Santes Creus: Boletín del Archivo Bibliográfico de Santes Creus, 5 (1978), pp. 445-447.
} 
en la historia política. Por eso, en las últimas décadas, el estudio de la reginalidad ${ }^{6}$ (Queenship) ha cambiado de paradigma y la biografía ha dejado de ser la línea de investigación principal. En estos momentos, siguiendo los avances teóricos dados por la historiografía anglosajona, se profundiza en la significación del papel político y social de estas mujeres, así como el proceso de construcción de su identidad pública. La reina consorte se observa desde prismas dispares para entender su presencia dentro de la institución monárquica ${ }^{7}$ y de las relaciones de poder de la corte medieval, analizando las estructuras de sus casas y los vínculos existentes entre los miembros de las mismas ${ }^{8}$. Tampoco se olvida la influencia de estas mujeres sobre el territorio, ya que gracias a la donación de rentas y jurisdicciones como dote y arras en su matrimonio ejercieron no sólo como representantes de la institución monárquica sino también como señoras con jurisdicción directa ${ }^{9}$.

6 Nuria Silleras, "Queenship en la Corona de Aragón en la baja Edad Media: Estudio y propuesta terminológica", La Corónica. A Journal of Medieval Hispanic Languages, Literatures \& Cultures, 1 (2003), pp. 119-133. Sin embargo, el término "reginalidad" no ha sido aceptado por la Real Academia de la Lengua ni incluido en el diccionario de la RAE, aunque gran parte de la historiografía especialista en habla hispana utiliza este término, apoyándose en el uso que se hace en la documentación medieval del término «reginal». Ver Diana Pelaz Flores y Ma Isabel del Val Valdivieso, "La Historia de las Mujeres...", pp. 101-127; y $\mathrm{M}^{\mathrm{a}}$ del Carmen García Herrero, "Los varones jóvenes en la correspondencia de María de Castilla, reina de Aragón”, Edad Media. Revista de Historia, 13 (2012), pp. 241-267.

7 Hoy en día encontramos una gran cantidad de trabajos que resaltan el papel de la reina en la monarquía medieval, por eso, hemos decidido seleccionar unos pocos: John CARmi PARson, Medieval Queenship, ed. Palgrave Macmillan, Nueva York, 1998; Murielle Gaude-Ferragu, Queenship in Medieval France, 1300-1500, ed. Palgrave Macmillan, New York, 2016; William LaYher, Queenship and Voice in Medieval Northern Europe, ed. Palgrave MacMillan, New York, 2010; María Jesús Fuente, Reinas medievales en los reinos hispánicos, ed. La esfera libros, 2004; María Jesús Fuente, “¿Reina la reina? Mujeres en la cúspide del poder en los reinos hispánicos de la Edad Media (siglos VI-XIII)", Espacio, Tiempo y Forma, serie III, Historia Medieval, 16 (2003), pp. 53-71; Theresa EARenfight, Queenship in Medieval Europe, ed. Palgrave Macmillan, Nueva York, 2012; Elena WoodaCre, Queenship in the Mediterranean: Negotiating the Role of the Queen in the Medieval and Early Modern Eras, Elena Woodacre (ed.), ed. Palgrave Macmillan, Nueva York, 2013; Joana Laynesmith, The Last Medieval Queens: English Queenship, 1145-1503, ed. Oxford University Press, Oxford, 2004.

8 Del mismo modo, el tema de la Casa de la Reina todavía es uno de los puntos de estudio de la reginalidad que más falta por dilucidar. Sin embargo, sí encontramos importantes estudios sobre el tema en: Manuela Santos Silva, "A Casa e o Património da Rainha de Portugal D. Filipa de Lencastre: um ponto de partida para o conhecimento da Casa das Rainhas na Idade Média", Revista Signum, 11 (2010), pp. 207-227; Fernando Serrano Larrayoz, "La casa y la mesa de la reina Blanca de Navarra (1443)", Anuario de estudios medievales, 30 (2000), pp. 157-234; Teresa Martialay Sacristán, "La Casa de Isabel, princesa y reina", Evolución y estructura de la Casa Real de Castilla, Andrés Gambra, Félix Labrador (dir.), ed. Polifemo, Madrid, 2011, vol. 1, pp. 197-226; Félix LABRADOR, "La influencia de la Casa de Castilla en la organización de la Casa de las Reinas hispanas", Evolución y estructura de la Casa Real de Castilla, Andrés Gambra, Félix Labrador (dirs.), ed. Polifemo, Madrid, 2011, vol. 1, pp. 227-262; Manuela Santos SiLva, "Os primórdios da Casa das rainhas de Portugal", Raízes Medievais do Brasil Moderno, ed. Academia Portuguesa de História, Lisboa, 2008, pp. 27-41; María NARBonA, "De casa de la senyora reyna. L'entourage domestique de Marie de Castille, épouse d'Alphonse le Magnanime (1416-1458)", Les entourages princiers à la fin du Moyen Âge, Alexandra Beauchamp (ed.), ed. Casa Velázquez, Madrid, 2013, pp. 151-167.

9 Cada vez son más las investigaciones que analizan el estado señorial de las reinas y el uso dado a las rentas de las mismas: Ana DronzeK, "Women and Property conflicts in Late Medieval England", Women and Wealth in Late Medieval Europe, Theresa Earenfight (ed.), ed. Palgrave Macmillan, Nueva York, 2010, pp. 
Un caso singular que ha despertado un interés especial en la investigación ha sido el del ejercicio de las reinas de la Corona de Aragón como lugartenientes reales ${ }^{10}$. La historiografía, particularmente la referida al ámbito internacional, ha visto en estas designaciones únicas a nivel europeo ${ }^{11}$ un ejemplo de la importancia que tenía la relación entre los monarcas, incluso a nivel político y que llegaba a manifestarse en el panorama institucional de la monarquía. Exactamente, la hipótesis defendida por historiadores

187-207; Manuela Santos SiLVA, "El señorío urbano de las reinas-consortes de Portugal (siglos XII-XV)", Ser Mujer en la ciudad medieval Europea, Jesús Ángel Solórzano, Beatriz Arízaga, Amélia Andrade (eds.), ed. Instituto de Estudios Riojanos, Logroño, 2013, pp. 271-288; Manuela SAnTos SiLVA, "Small Towns Belonging to the Medieval Queens of Portugal. Distinctiveness, Taxation, Jurisdiction", Petites villes européennes au Bas Moyen Âge: Perspectives de recherche, Adelaide Millán da Costa, IEM-Instituto de Estudos Medievais, Lisboa, 2013, pp. 125-136; Theresa Earenfight, "Royal Finances in the Reign of Maria of Castile, QueenLieutenant of the Crown of Aragon, 1432-1453", Women and Wealth in Late Medieval Europe, Theresa Earenfight (ed.), ed. Palgrave Macmillan, Nueva York, 2010, pp. 229-244; Diana Pelaz Flores, "El poder de la reina a través del señorío de sus tierras: el ejemplo de Arévalo en la Baja Edad Media", Mundos Medievales: espacios, sociedades y poder: homenaje al profesor José Ángel García de Cortázar y Ruiz de Aguirre, Beatriz Arízaga et alii (eds.), ed. Publican, Ediciones de la Universidad de Cantabria, 2012, vol. 2, pp. 1731-1742; Ana Maria S.A. Rodrigues y Manuela SANTos Silva, "Private properties, seignorial tributes and jurisdictionals rents: the income of the queens of Portugal in the Late Middle Ages", Women and Wealth in Late Medieval Europe, Theresa Earenfight (ed.), ed. Palgrave Macmillan, Nueva York, 2010, pp. 209-228; Víctor MuÑoz Gómez, "Mujeres aristocráticas y el poder del linaje en la Castilla bajomedieval: la reina viuda Leonor de Albuquerque y la defensa de la 'casa' real de Aragón (1416-1435)", Reginae Iberiae: el poder regio femenino en los reinos medievales peninsulares, Miguel García Fernández y Silvia Cernadas Martínez (eds.), Universidad de Santiago de Compostela, Servizo de Publicacións e Intercambio Científico, Santiago de Compostela, 2015, pp. 245-275; Sebastian RoeberT, "«Que nos tenemus a dicto Domino Rege pro camera assignata». Desarrollo, administración y significado de los bienes reginales de Leonor de Sicília (1349-1375)", Anuario de Estudios Medievales, 46 (2016), pp. 231-268.

10 Son significativamente conocidos los casos de María de Castilla y María de Luna quienes fueron repetidamente nombradas lugartenientes, y en el caso de la primera por un período de casi treinta años. En este sentido cabe destacar las publicaciones de Theresa Earenfight, "Maria of Castile, ruler or figurehead? A preliminary study in Aragonese queenship", Mediterranean studies, 4 (1994), pp. 45-62; Theresa EARENFIGHT, Queenship, politics and government in the medieval Crown of Aragon: The lieutenancy of Maria of Castile, 1420-1423 and 1432-1453, ed. Fordham University press, Nueva York, 1997; Theresa EARENFight, The King's Other Body: Maria of Castile and the Crown of Aragon, ed. University of Pennsylvania Press, Pennsylvania, 2009. En el caso de María de Luna tendríamos que destacar: Nuria Silleras, María de Luna. Poder, piedad y patronazgo de una reina bajomedieval, ed. Institución Fernando el Católico, Consejo Superior de Investigaciones Científicas, Zaragoza, 2012.

11 A nivel europeo encontramos regencias, en las que minoría de edad del monarca suponía que su madre debiera hacerse cargo de la monarquía y el gobierno junto con un consejo, pero no como la Lugartenencia de la reina aragonesa en la que el rey designa a su esposa como su sustituto durante un tiempo de ausencia. Un buen estudio sobre el caso de las regencias es: Ana Maria S.A. RodRiguEs, "Las regencias femeninas en los reinos ibéricos medievales: ¿fue el caso portugués una singularidad?", Anuario de Estudios Medievales, 46 (2016), pp. 301-328. Además encontramos otros estudios para el contexto europeo de la regencia en: Roger ColLins, "Queens-Dowager and Queens-Regent in the Tenth-Century León and Navarre", Medieval Queenship, John Carmi Parsons (ed.), St. Martin's Press, Nueva York, 1993, pp. 79-92; Fanny Cosandey, "Puissance maternelle et pouvoir politique: la régence des reines mères", Clio, Histoire, Femmes et Sociétés, 21 (2005), pp. 69-90; Ana ECHEVARRía, Catalina de Lancaster. Reina regente de Castilla (1372-1418), ed. Nerea, Hondarribia, 2002; Miriam SHADIs, Berenguela of Castile (1180-1246) and Political Women of the High Middle Ages, ed. Palgrave Macmillan, Nueva York, 2009; Joana LaYnesmith, The Last Medieval Queens: English Queenship, 1145-1503, ed. Oxford University Press, Oxford, 2004. 
como Theresa Earenfight mantiene que la Lugartenencia es la muestra de la colaboración o partnership desarrollada entre los esposos, entre rey y reina, para conjuntamente fomentar los objetivos de la monarquía como institución ${ }^{12}$. Este argumento, en el que nos detendremos más adelante, se ha convertido en la piedra angular de muchos de los estudios realizados sobre la Lugartenencia aragonesa.

Sin embargo, parte del análisis hecho hasta la fecha sobre la Lugartenencia de las reinas tiene todavía muchos aspectos por clarificar. Por ello, en el presente artículo, intentaremos elaborar una aproximación más detallada al ejercicio de la Lugartenencia real de las reinas aragonesas y, concretamente, sobre el origen de la institución, la primera designación, los motivos que llevaron a dicha designación y el listado de reinas que ejercieron este oficio. Asimismo, nuestro análisis concluirá con una reflexión teórica acerca de la designación de la reina como lugarteniente.

\section{La Lugartenencia real en la Corona de Aragón}

\subsection{Orígenes}

Jesús Lalinde afirmaba que "la creación de una administración real que representara los poderes del rey sobre el territorio fue el fruto de una larga gestación durante siglos, esculpiendo una trayectoria sinuosa, con una evolución marcada por los retornos y los avances"13. El proceso de su creación, como otros aspectos de la gobernabilidad monárquica de los reinos medievales, dependía de su relación con el territorio sobre el que ejercía dicho dominio. Las modificaciones en su relación con el territorio, ya fuera por la cesión de competencias o por la ampliación del mismo, llevaban a los monarcas a organizar el panorama administrativo con figuras que suplieran los vacíos de poder provocados por la distancia entre el territorio, sus habitantes y el gobernante. ${ }^{14} \mathrm{Sin}$ embargo, en este paulatino avance en la configuración de la administración gubernamental dependiente del rey, la consolidación de la misma así como del poder regio medieval, se vuelve muy complicada sobre un territorio fragmentado, no solo en distintos reinos sino también en jurisdicciones que escapan al monarca, y donde éste es visto como un ente no solo lejano sino también muy ajeno a su dominio ${ }^{15}$.

Por ello, cuando hablamos de la representación del monarca en las más altas cotas de poder es cuando podemos decir que estamos ante el reflejo de la consolidación real

12 Theresa Earenfight, The King's Other Body..., p. 22.

13 Jesús Lalinde Abadía, La Gobernación General en la Corona de Aragón, ed. Consejo Superior de Investigaciones Científicas, Madrid, 1963.

14 Enric Guinot Rodríguez, "Organització del poder, organització del territori en temps de Jaume I", Jaume I $i$ el seu temps 800 anys després, Rafael Narbona (coord.), ed. Fundació Jaume II el Just, València, 2012, p. 74.

15 Flocel SABATÉ, "Estados, soberanía y modelo político en la Cataluña bajomedieval", Aragón en la Edad Media, 21 (2009), p. 246. 
y catalizadora de las tensiones entre los vectores del poder medieval ${ }^{16}$. Representar al rey con la totalidad de sus poderes sin poner su posición en cuestión mostraba la fortaleza de la legitimidad del gobierno del rey y del sistema de la representación y de las magistraturas que dependían de manera efectiva de éste. Y aunque significaba que la autoridad del rey era indiscutible, hasta el punto de permitir que otros ejercieran sus competencias sin sentirse desafiado, no quiere decir que el nacimiento y la organización de cada engranaje del sistema fuera planificado y comprendido como será al final. Así, a lo largo de este proceso de construcción de su aparato gubernamental, la monarquía creaba oficios dependiendo de las urgencias que acusaran para mantener los organismos de gobierno en funcionamiento, en muchos casos por las necesidades del esquema territorial de sus dominios.

En una circunstancia como la anterior nació la Lugartenencia real en la Corona de Aragón, en una coyuntura que combinaba la necesidad con la planificación administrativa. A lo largo del siglo XII, surgieron representantes delegados del rey, lugartenientes, en los territorios más periféricos de la Corona de Aragón, como el Rosellón y la Cerdaña ${ }^{17}$. Aunque el afianzamiento y consolidación de estos delegados regios se debe a Jaime I, quien en buena medida prácticamente duplicó la extensión de sus antiguos dominios (Aragón y Cataluña) después de la conquista sobre los musulmanes del Reino insular de Mallorca y la incorporación del Reino de Valencia hasta la línea Biar-Bussot ${ }^{18}$. En cuestión de veinte años el Conquistador había doblado el territorio heredado de sus antepasados y aunque esto le otorgaba una gran fama y renombre en toda Europa ${ }^{19}$, para su ejercicio como monarca la presencia en los territorios se tornaba imposible ${ }^{20}$. En consecuencia, la Lugartenencia parecía una opción eficaz para mantener la visibilidad de la gobernabilidad monárquica a través de servidores y oficiales vinculados a la figura del rey que cumplieran con la función de mostrar la presencia del poder real sobre el territorio y evitar una sensación de desaparición de esta autoridad ante el aumento de territorio en el que debía estar presente. El modelo jurídico se encontró en figuras

16 Flocel SABATÉ, "La governació al Principat de Catalunya i als comtats del Rosselló i la Cerdanya", Anales de la Universidad de Alicante. Historia medieval, 12 (1999), p. 21.

17 Jesús Lalinde Abadía, La Gobernación General..., p. 6.

18 Este hecho es relatado en gran cantidad de artículos, libros y manuales, así que escogeremos algunos de carácter general: Antoni Furió I Diego, Historia del País Valencià, ed. Alfons el Magnànim, València, 1995; Antoni Furió I Diego, El rei conqueridor: Jaime I: entre la història i la llegenda, ed. Bromera, Alzira, 2008; Ernest Belenguer, Jaume I i el seu regnat, ed. Pagès, Lleida, 2007.

19 En un pasaje del Llibre del Feits, Jaime I deja claro que la conquista de Mallorca le ha ganado renombre internacional y ha aumentado su valía como rey: E sobre aquestes paraules nos fom somoguts, e per ço quan desloauen Maylorques, e loaven Valencia. E dixem: Ara volets que us digam con nos sembla que la pendrem? Nós no hauem muyler, e parlen nos la fiyla del Rey d'Ongria, e el duch D'oltalrich parla ho Lapostoli, e nos hauem hauda fiyla de Rey dels pus honrats del mon: e iassia quens uuylan donar la fiyla del duch Dostalrich, ab mes hauer no la pendrem, que mes amam la fiyla del Rey Dongria, que quant nos no valiem tant nos donaren la fiyla del Rey de Castela don Alfonso, ben es rao que ara quan ualem mes que prengam fiyla de Rey. El llibre del feits del rei En Jaume, ed. Antoni Ferrando i Vicent Josep Escartí, Acadèmia Valenciana de la Llengua, València, 2010, cap. 119.

20 Jesús Lalinde Abadía, "Ensayo de tipología orgánica de la administración en la historia de España", Annali della Fondazione italiana per la storia amministrativa, 4 (1967), pp. 10-14. 
administrativas públicas empleadas en la Antigüedad romana, cuya esencia intrínseca era la idea de la representatividad del poder central ${ }^{21}$.

De hecho, la alta representación del rey en el territorio no es una figura administrativa únicamente aragonesa, en otras monarquías peninsulares eran habituales otras figuras de sustitución del monarca ante su ausencia. Un ejemplo sería la aparición de la figura de los adelantados en las Siete Partidas ${ }^{22}$.

\subsection{Los primeros momentos}

Durante el siglo XIII, la Lugartenencia Real en la Corona de Aragón tuvo unos rasgos poco definidos, producto de este largo proceso de gestación, que se entremezclan con las competencias de otra magistratura surgida en una cronología semejante, la Procuración General. En los primeros momentos, ambas instituciones llegaron a ser denominadas indistintamente, aunque internamente y con el paso del tiempo se diferenciarían de manera definitiva.

Por su parte, el oficio de la Procuración surgió durante la minoría de edad de Jaime ${ }^{23}$. A diferencia de la Lugartenencia, la Procuración se convirtió, paulatinamente, en una magistratura estable, con una jurisdicción ordinaria que derivaba en el procurador por la asunción del cargo. El momento del cambio o evolución llegaría durante el período 1250 y 1310 cuando la Procuración adquiriría progresivamente un carácter territorial diferenciado, implicando la aparición de un procurador para cada una de las entidades administrativas (procuraciones) en las que se dividía la Corona de Aragón. A su vez, con el surgimiento de procuradores territoriales se comenzó a designar al heredero de la monarquía como Procurador General de toda la Corona. Más adelante, ya a mediados del siglo XIV, la Procuración pasaría a denominarse Gobernación y al frente de la misma estaría el Gobernador General ${ }^{24}$. La intención fue afianzar la Procuración o

${ }_{21}$ José Vicente CABezuelo, Poder público y administración territorial en el Reino de Valencia 1239-1348, el oficio de la Procuración, ed. Conselleria de Presidència, Valencia, 1998, p. 116.

22 José Vicente CABezuelo, "El poder real en la Murcia aragonesa a través del oficio de la Procuración 1296-1304", Anales de la Universidad de Alicante. Historia medieval, 11 (1996-1997), p. 81; José Vicente Cabezuelo, Poder público ..., p. 114; José María Ortuño, "El adelantado en las Partidas", Miscelánea Medieval Murciana, 18 (1993-1994), pp. 162, Cita las Siete Partidas, II, 9, 22. Las Partidas vinculan al adelantado con los oficiales romanos: "Et teniéndolo por honra muy señalada, llamaron a los que trahien las señas de los emperadores et los reyes primipilarius, que quiere tanto decir en latín como oficial que llevaba la primera seña del grant señor, et aún le llamaron otrosí praeses legionum, que quiere tanto decir como adelantado sobre las compañas de las huestes: et esto era porque ellos juzgaban los grandes pleytos que acaescian en ellas..."

23 José Vicente Cabezuelo, Poder público..., p. 116.

24 Además de la obra general de Jesús Lalinde Abadía, ver op. cit 13, encontramos estudios concretos de las diferentes gobernaciones: Esteban SARASA SÁnchez, "La Gobernación General en Aragón durante la Baja Edad Media", Anales de la Universidad de Alicante. Historia medieval, 12 (1999), pp. 9-20; Maria Teresa Ferrer i Mallol, Organització i defensa d'un territori fronterer: la governació d'Oriola en el segle XIV, Institució Milà i Fontanals, 1990; Jose Vicente CABEzuelo, "Procuració versus governació. El reino de Valencia ante la reforma gubernativa de 1344”, Anuario de Estudios Medievales, 25 (1995), pp. 571-592. 
Gobernación como un sistema de gobierno territorial efectivo y poner al frente de la institución al heredero de la Corona, asentando figurativamente su poder como segundo en la gobierno de la monarquía ${ }^{25}$.

En cuanto a la naturaleza intrínseca de su jurisdicción también se evidencian importantes diferencias. El procurador o gobernador es el mayor oficio jurisdiccional después del monarca ${ }^{26}$, mientras que el lugarteniente es un cargo extraordinario, nombrado en casos puntuales para ocupar el lugar propio del monarca. De aquí que el origen de la jurisdicción de ambos sea diferente. La posesión de un oficio conllevaba la garantía del ejercicio legal de la jurisdicción inherente al mismo, siendo por tanto, una jurisdicción ordinaria, hasta el punto que puede tener sustitutos. En resumidas cuentas, podemos decir que la Procuración era un oficio de jurisdicción ordinaria mientras que la Lugartenencia fue un cargo de jurisdicción delegada y extraordinaria que no pasaría a ser permanente sino que su duración será determinada por los motivos que impulsaron la contingencia de la elección ${ }^{27}$.

Por otra parte, el ejercicio de la Lugartenencia consistió en la delegación de las atribuciones propias y reservadas para el rey en un miembro de la familia real o de fuera de ésta pero que gozara de la confianza directa del monarca, para que durante un período limitado por la ausencia o indisposición de éste, se hiciera cargo de determinadas funciones. La asunción de este cargo por parte de las reinas de la Corona de Aragón constituye un impulso dentro de la evolución del rol propio de la reina consorte y representa un punto de inflexión en su significación política y social dentro de la sociedad medieval, escenificando el rol que la reina asumía en todos los ámbitos de la vida pública, incluido el político.

Entendida la naturaleza jurídica e institucional de la Lugartenencia real, a continuación procederemos a analizar el primer ejercicio de la Lugartenencia real por parte de una reina consorte en la Corona de Aragón.

\section{La primera Lugartenencia de una reina de Aragón}

\subsection{La primera reina lugarteniente}

El 8 de julio de 1359, la reina Leonor de Sicilia, tercera esposa de Pedro el Ceremonioso, enviaba la siguiente solicitud a diferentes miembros del estamento eclesiástico de Cataluña:

25 José Vicente Cabezuelo, Poder público..., pp. 342-343.

26 José Vicente Cabezuelo, Poder público..., pp. 406-408.

27 Para ampliar sobre las diferencias entre jurisdicción ordinaria y extraordinaria José GARCía MARín, El oficio público en Castilla durante la Baja Edad Media, ed. Instituto Nacional de Administración Pública, Sevilla, 1974. Según el autor, las características diferenciadoras básicas son la titularidad, la duración, la base territorial, el número de causas y la posibilidad de un sustituto. Visto en José Vicente CABezuelo, Poder público..., pp. 650, ver nota 1.693 . 
"La Reyna d'Aragó,

Com per alcuns ardits, los quals ara de present havem haüts del Senyor Rei, que així com sabets és en les illes de Mallorches, en les quals, axí mateix, és son enemich, lo Rey de Castella, qui s'és crescut estol e estan tot jorn per combatre, nós hajam necessitat de vostre consell, d'alcuns altres prelats e altres persones de la terra del Senyor Rey. Per ço, de part del dit Senyor, del qual tenim loch, e de la nostra, aytant com afectuosament podem, vos pregam, deïm e manam, e encara per lo deute de naturalesa de la qual sots tengut al dit Senyor, axi com a senyor natural e Rey e príncep vostre, vos requerim que dins de $\mathrm{V}$ dies aprés que la present letra haurets reebuda siats ací en Barchinona (...)"28

Esta misiva es la primera actuación documentada de una reina de la Corona de Aragón como lugarteniente real. Como se puede comprobar, la reina Leonor solicita la reunión en Barcelona de los prelados de Catalunya para disponer de su consejo. La petición no solo es rubricada por la reina, sino que procede de la reina y del rey, porque a pesar de la ausencia de éste, quien se encontraba entonces en Mallorca luchando contra el rey de Castilla ${ }^{29}$, la reina ocupa su lugar. Así lo hace saber cuando utiliza la fórmula "del qual tenim loch", es decir, de quien tenemos el lugar. Es la primera vez que una reina utiliza esta fórmula y mediante la misma se iniciaría así el ejercicio de la Lugartenencia real por las reinas consortes.

La autoridad de la reina se concibe por la asunción del poder del rey de manera temporal y excepcional, por lo que la orden no proviene de la reina sino del rey y la reina, de un mismo poder, la monarquía, que en ausencia del rey tenía a la reina como su representante. A la reina, pues, se le confía "el lugar del rey", esto es, su posición en el marco institucional y social durante la ausencia del mismo. Con esta fórmula, por lo tanto, la reina se muestra constituida como la lugarteniente general de la Corona cuya autoridad le es delegada por el monarca. Por ello, mientras el rey se encontraba al frente de la flota combatiendo al rey de Castilla en el asedio a Ibiza, la reina se mantuvo al frente del aparato burocrático y administrativo de la Corona, que no quedó desatendido por la ausencia del rey sino gestionado por el alter ego de éste ${ }^{30}$. La reina Leonor se convertía así en el alter ego del monarca quien, en su ausencia, debía mantener coordinados los asuntos estratégicos de la guerra del rey.

La expresión de esta dualidad se manifiesta en la expresión "de part del dit Senyor, del qual tenim loch, e de la nostra", con la que la reina se muestra en posesión de la autoridad gubernamental y con capacidad para ejercer el poder real, o propio del rey, para

28 Archivo de la Corona de Aragón (ACA), Real Cancillería (RC), registro (reg.) 1568, fol. 1r.

29 Para más información sobre esta contienda: José Vicente CABEZUELO, "La guerra en el mar. La campaña marítima castellana de 1359 y la defensa litoral de la Corona de Aragón", eHumanista/IVITRA, 7 (2015), pp. 116-150.

${ }_{30}$ La expresión alter nós es utilizada por el propio Alfonso el Magnánimo en una de las designaciones a María de Castilla, ver Theresa Earenfight, The King's Other Body..., pp.1-18. 
ordenar cualquier mandato a los oficiales y particulares de la Corona por la ausencia de éste. Esta fórmula cancilleresca se entiende como un elemento de retórica política para la exposición y afirmación de la autoridad y poder de la consorte para ejercer las funciones políticas propias del monarca. Ahondando en los formulismos cancillerescos, vemos que la intitulación es la usada por la reina hasta el momento y no encontramos en ella ninguna modificación: Leonor de Sicilia sigue apareciendo como reina consorte, "la Reyna d'Aragó", sin mostrar ningún cambio en su atribución particular. El cambio particular aparece en el cuerpo de este texto cuando interpela al lector remarcando la nueva naturaleza de su autoridad, advirtiendo que en ese momento quien se dirige al lector no es solo la reina consorte sino también el alter ego del monarca.

La nueva posición de la consorte también quedó ratificada diplomáticamente. La organización de los registros de la Cancillería de los reyes de Aragón conservados en el Archivo de la Corona de Aragón de Barcelona está articulada siguiendo las normas básicas de la archivística y la biblioteconomía, estas son, los principios de procedencia y de orden natural. Así, en la sucesión de los registros del monarca en cuestión siempre aparecen en un ámbito separado los registros de sus esposas e hijos durante el tiempo que fueron reinas e infantes aragoneses ${ }^{31}$. Al igual que en el caso de los reyes de Aragón, los registros de las reinas mantienen los principios de procedencia y orden natural para poder mantener el sentido propio del archivo real de la monarquía. Sin embargo, entre los registros de Leonor de Sicilia ${ }^{32}$ aparecen dos registros que documentan un mismo espacio de tiempo. Por un lado, el registro 1.567, que abarca los años 1358 a 1360, y, por otro, el registro 1.568 , que solo abarca el período de julio a agosto de 1359 y en el cual encontramos el documento que nos ocupa ${ }^{33}$. La creación de un registro diferenciado al anterior implicaba la voluntad explícita de creación de un volumen documental separado para recoger unas acciones que por necesidad debían tener una naturaleza jurídica diferente a las recogidas en el volumen 1.567. Recoger y diferenciar los actos de la reina consorte en un volumen de la Cancillería particular para el verano de 1359, además en una coyuntura militar y política compleja por las campañas de la Guerra de

\footnotetext{
31 Sobre el Archivo de la Corona de Aragón: Carlos López Rodríguez, "Orígenes del Archivo de la Corona de Aragón, en tiempos, Archivo Real de Barcelona”, Hispania, 67 (2007), pp. 413-454; Federico UdinA Martorell, Guía histórica y descriptiva del Archivo de la Corona de Aragón, ed. Dirección General de Bellas Artes y Archivos, Madrid, 1986; Carlos López Rodríguez, ¿Qué es el Archivo de la Corona de Aragón?, Mira Editores, Zaragoza, 2007.

32 Leonor de Sicilia era hija de Pedro II de Sicilia y Isabel de Carintia, se convirtió en la tercera esposa de Pedro el Ceremonioso en 1349 y la primera en proporcionarle dos hijos varones: Juan, futuro Juan I, rey de la Corona de Aragón entre 1387 y 1396 y Martín I rey de la Corona de Aragón 1396 y 1410. El matrimonio entre Pedro y Leonor fue concertado por los intereses políticos que el rey podía obtener sobre la isla de Sicilia. La reina moriría en Lleida en 1375, después de 26 años como reina consorte de la Corona de Aragón y cediendo a su segundo hijo sus derechos sobre la isla de Sicilia. Se pueden encontrar más datos sobre la reina Leonor en: Ulla DeiBel, "La Reyna Elionor ... “, pp. 349-453.

33 De Leonor de Sicilia se conserva un total de 23 registros de Cancillería en el ACA, cuyas signaturas van del número 1.563 al 1.585 .
} 
los Dos Pedros ${ }^{34}$, se debe a la naturaleza de las acciones emitidas por la consorte. La inequívoca confirmación de que la reina Leonor actúa como lugarteniente se encuentra, sin embargo, en el registro de Cancillería 1567, que anteriormente citábamos, ya que también contiene mandamientos de la reina durante el período 1358 a 1360. Así, en un documento notarial fechado el día 11 de julio de 1359 recogido en ese volumen encontramos a la reina hablando de sí misma como "locumtenens" 35 . De manera tangencial, se ha incluido en dicho volumen un documento expedido por la Reina como lugarteniente en el que se reconoce un pago hecho por el rey en el mes anterior de una elevada suma de florines por el armado de dos galeras para la guerra. Al tratarse de un documento notarial, la Reina hizo uso de su estatus oficial como lugarteniente del rey Pedro el Ceremonioso para poder certificar el documento.

De este modo y gracias al nombramiento del rey Pedro a su esposa como lugarteniente, la reina pudo articular los preparativos necesarios para que la ausencia del rey no supusiera una paralización burocrática ni de la resolución de asuntos tratados previamente a la marcha del rey. La posición delegada en la reina, permitió al monarca mantenerse al frente de su flota y tropas, mientras que en su condición de lugarteniente Leonor de Sicilia continuó la agenda política de ambos monarcas. Para tal fin, instó a la construcción de nuevos navíos para la flota ${ }^{36}$, buscó financiación para las campañas navales ${ }^{37} \mathrm{y}$ se aseguró de que Enrique de Trastámara, capitán general de Aragón, no desatendiera la frontera entre Aragón y Castilla ${ }^{38}$, entre otros aspectos. En esencia, antes de su nombramiento como lugarteniente, Leonor no poseía poder político en la Corona de Aragón más allá del poder en relación derivado de su proximidad al rey, así como su capacidad de actuar como señora en las villas y lugares donados por el rey o comprados por ella misma con tal fin. Con el nombramiento como lugarteniente, ambos pasaban a compartir las mismas competencias gubernativas, creándose una simultaneidad en el ejercicio de la soberanía, entre rey y reina, sobre los súbditos de la monarquía.

Una vez que hemos constatado como Leonor de Sicilia ejerció como lugarteniente de su marido, precisaremos cuáles fueron los motivos que determinaron y justificaron su designación como lugarteniente del rey Pedro el Ceremonioso.

\footnotetext{
34 La Guerra de los Dos Pedros es como se conoce al conflicto que enfrentó a la Corona de Aragón y a la Corona de Castilla entre 1356 y 1375, aunque las hostilidades cesaron en 1365, por diversos motivos, como el reparto del Reino de Murcia entre ambas Coronas, los derechos de la reina viuda Leonor de Castilla y sus hijos, los infantes Fernando y Juan; la alianza con Génova de Castilla entre otros aspectos. Hay bastantes trabajos que han tratado parcialmente este período pero el más importante quizás sea: Mario LAFUENTE GómEZ, La guerra de los Dos Pedros en Aragón (1356-1366) Impacto y trascendencia de un conflicto bajomedieval, Universidad de Zaragoza, 2009, Tesis Doctoral.

35 ACA, RC, reg. 1.567, fol. 120v. "Noverint universi quod Nos Alionora, Dei gratia Regina Aragone, etc., ac illustrissimi principis et Domini Petri, Dei gratia Regis Aragone, consors et locumtenens in Regnis".

36 Sobre el armamento de la flota ver: ACA, RC, reg. 1.568, fols. 3r-3v; 4r; 4v; 5r; 5v; 13v; 14r-15v, 36r$38 \mathrm{v}$.

37 Sobre la financiación ver: ACA, RC, reg. 1.568, fols. 7v, 12r-v; 39r-39v; 43r-43v; 48v; 85r-86v.

38 Sobre la defensa de la frontera de Aragón ver: ACA, RC, reg. 1.568, fols. 11r-11v; 46r-47v; 60r-73r.
} 


\subsection{Los motivos de la elección}

La reina Leonor podía exhibir públicamente su participación en el gobierno de la monarquía aragonesa porque las circunstancias que anteriormente habían rodeado y condicionado su persona y la del rey lo permitían.

En primer lugar, la reina Leonor era una reina ungida y coronada. En 1352 se celebró la solemne ceremonia en la Seo de Zaragoza, delante de las familias de la nobleza más importantes $^{39}$. En la historia de la Corona de Aragón, solo cinco reinas fueron coronadas, convirtiendo la coronación de cada una de ellas en un acto de valor simbólico, legitimador y propagandístico ${ }^{40}$. Poco sabemos de dicha coronación; sin embargo, conservamos las ordenanzas sobre "la manera com les reynes d'Aragó se faran consegrar y els reys d'Aragó les coronaran" redactadas por la Cancillería del Ceremonioso y revisadas por el mismo rey Pedro un año después de coronar a su mujer ${ }^{41}$. La ordenanza, al ser impulsada y supervisada por el soberano, se convierte en una codificación del mensaje de la monarquía aragonesa como institución a través de una escenificación de un rito cargado de simbolismo, que a su vez, en la plasmación material y social, se convierte en un acto de ordenación y jerarquización que ensalza la preeminencia del rey y la reina sobre el conjunto social.

El texto se inicia con una justificación, extraída del Génesis, del acto de coronación de la reina ${ }^{42}$. La mujer en Aragón, por tradición, nunca ostentó el poder de la Corona, por lo que el acto de la coronación, símbolo de la conexión directa entre el monarca y su oficio de gobernante, necesitaba una especial justificación en lo que atañía a la coronación de la esposa del rey. Según la cita bíblica empleada en el texto, la mujer había sido creada por la necesidad del hombre de tener una compañera y por eso se toma una parte del centro del cuerpo de éste para crearla.

El vocablo utilizado en la ordenanza describe a la reina como la "companyona", la compañera del rey. En ese sentido y siguiendo la retórica impulsada desde la monarquía, en la correspondencia epistolar entre ambos monarcas observamos que la expresión "la vostra humil companyona"43 es la usada por la reina Leonor para referirse a sí misma como remitente y será la que posteriormente utilizarán las consortes de la Corona de

\footnotetext{
39 Jaume RIERA SANS, "La coronació de la Reina Elionor (1352)", Acta historica et archaelogica mediaevalia, 26 (2005), pp. 485-492.

40 Nuria Silleras, "Creada a su imagen y semejanza: la coronación de la Reina de Aragón según las Ordenaciones de Pedro el Ceremonioso", Lusitania sacra: revista do Centro de Estudos de Historia Eclesiastica, 31 (2015), pp. 107-128.

41 Ordinacions de la casa $i$ cort de Pere el Cerimoniós, ed. Francisco Gimeno, Daniel Gozalbo y Josep Trench, Publicacions de la Universitat de València, Valencia, 2009.

42 Génesis, 2:18. "Scrit és en la Sancta Escriptura que, aprés les coses creades, Déu omnipotent creà l'om, e veent que l'hom tot sol no era profitós, dix: No és bo hom ésser sol, façam a ell ajudatori semblant a ell'. En: Ordinacions de la casa ..., p. 266.

43 Por ejemplo, por citar un caso concreto en Leonor de Sicilia: ACA, Real Cancillería, reg. 1.573, fol. $18 \mathrm{v}$.
} 
Aragón. Mediante esta expresión se transmite intencionadamente una retórica difusora ${ }^{44}$ de la postura política de la monarquía, en la que rey y reina comparten y colaboran en el gobierno del reino. Otros formulismos cancillerescos, como el castellano Reynante(s) en vno $o^{45}$, enfatizan también esta misma idea en el escenario político ibérico, confirmando que esta realidad no es un hecho aislado aragonés sino la concepción de la monarquía de la relación entre rey y reina. La reina, como esposa del rey, se convierte, por el acto sagrado del matrimonio, en la colaboradora más directa del rey, recayendo en ella parte de la empresa gubernativa y ordenadora de la Corona y de los aspectos sociales y religiosos con los que la monarquía construía su identidad o esencia en la sociedad medieval ${ }^{46}$.

De ahí que el acto de la coronación en sí mismo, es decir, el momento en que era puesta la corona real en la cabeza ungida de la reina junto con los otros emblemas del poder monárquico, debía llevarlo a cabo el propio rey ${ }^{47}$. Según la ordenanza, los monarcas comparten las gracias espirituales, pero la autoridad y el poder de la reina provienen de su relación con el rey. Este principio se evocaba durante el momento más trascendental de la ceremonia, ya que la corona era impuesta a la reina por quien le concedía la autoridad, su marido. Mediante el texto sobre la coronación, se enlaza con la designación de la reina Leonor como lugarteniente. La reina era la companyona del rey, pero en el caso de Leonor, además, se contaba con la legitimidad litúrgica de la unción y coronación, justificando su elección para el cargo.

Por otro lado, la designación de la consorte mantenía la estabilidad gubernativa para el monarca puesto que, como hemos visto, la posición de ésta dependía directamente de su relación con el rey, por lo que el monarca evitaba que su posición sufriera algún deterioro por la designación de un alter ego. Sin embargo, esto no se podía garantizar si se nombraba a una persona con la que no le unía tal relación de dependencia y confianza.

La situación de Pedro, incluso antes del inicio de su reinado, siempre había sido especialmente delicada. Hijo del rey Alfonso el Benigno y su primera esposa, Teresa de Entença, su padre se volvió a casar, una vez coronado rey, con la infanta castellana Leonor, hermana del rey Alfonso XI de Castilla ${ }^{48}$. En 1329 nacía el primer hijo varón de este matrimonio, Fernando, y con su nacimiento, a la vez que con las donaciones de dote y arras para la reina Leonor, el rey Alfonso enajenó prácticamente las principales ciudades y villas del Reino de Valencia que se encontraban en el Real Patrimonio del

\footnotetext{
44 José Manuel NiEto Soria, "Ceremonia y pompa para una monarquía: los Trastámara de Castilla", $\mathrm{Cu}$ adernos del CEMYR, 17 (2009), p. 57.

45 Diana Pelaz Flores, Reynante(s) en vno. Poder y representación de la Reina en la Corona de Castilla a lo largo del siglo XV, Universidad de Valladolid, 2015, Tesis doctoral inédita.

46 Afirmándose, así, el discurso teórico desarrollado por la historiografía especialista en reginalidad, de la que ya hemos hablado, op. cit. 5,6, 7, 8, 9 y 10 .

47 Ordinacions de la casa ..., p. 270.

48 Jesús Ernest Martínez, Santiago Sobrequés, i Enric Bagué, Els descendents de Pere el Gran: Alfons el Franc, Jaume II, Alfons el Benigne, ed. Vicens-Vives, Barcelona, 1954; Alejandra Recuero, "Doña Leonor: infanta castellana, reina aragonesa y elemento de discordia en las relaciones castellano-aragonesas en la primera mitad del siglo XIV”, Estudios Medievales Hispánicos, 2 (2013), pp. 221-240.
} 
monarca a excepción de Valencia. Además de éstas, otras donaciones como Albarracín o Tortosa aumentaban el poder territorial, jurisdiccional y económico del infante respecto a su hermanastro el futuro rey Pedro el Ceremonioso ${ }^{49}$. Después de la muerte del rey Alfonso, los hermanastros pleitearon por las rentas y jurisdicciones de las villas concedidas en las donaciones anteriores. En la mayoría de los casos solo se transfirió las rentas de las villas, dejando su jurisdicción en manos del nuevo monarca, el rey Pedro. Sin embargo, este conflicto fraguó una importante rivalidad entre los hermanastros y terminó con el exilio de la reina y los infantes a Castilla.

La enemistad entre Pedro y su hermanastro creció aun más cuando, en 1347, después del estallido de la Revuelta de la Unión en Aragón y Valencia, Fernando, sabiéndose heredero al trono, se vinculó a la nobleza aragonesa y luchó con ésta con la intención de avivar sus derechos como heredero legítimo por delante de los de la infanta Constanza, hija del rey Pedro ${ }^{50}$. Después de la derrota unionista de Épila y la victoria de Pedro en el conflicto bélico, el infante Fernando buscó refugio en la corte castellana, donde sabía que tendría un lugar privilegiado junto a su madre, Leonor. Poco tiempo después, con la llegada al trono de Pedro I de Castilla, Fernando sería nombrado adelantado mayor y canciller de Pedro I, además de ser concertado su matrimonio con la infanta María de Portugal en $1354^{51}$.

El año anterior al inicio de la Guerra de los Dos Pedros, en 1355, el infante Fernando renueva su fidelidad a Pedro I de Castilla, ya que sus opciones de llegar al trono de Aragón eran muy pocas desde el nacimiento, en 1350, del infante Juan, primogénito varón del rey Pedro el Ceremonioso. Al empezar el conflicto entre las dos coronas, el infante Fernando se encontraba del lado castellano y luchando contra el rey de Aragón, su hermanastro, en el sur del Reino de Valencia. Aprovechando la primera tregua de la contienda, la tregua de Tudela de 1357, se produjo un acercamiento entre los hermanastros, quienes se encontraron en La Cañada de Pozuelo y juraron un pacto en Teruel, en diciembre de $1357^{52}$, por el que el Ceremonioso concedía la práctica totalidad de aquello que solicitaba el infante, especialmente en lo tocante a sus derechos sobre villas concedidas en el testamento de su padre, el rey Alfonso. El año siguiente, siguiendo las condiciones del pacto, Fernando fue nombrado, en las Cortes del Reino de Valencia, Procurador General de la Corona, respetando siempre que la sucesión al rey Pedro recaía en el infante Juan y no en él mismo. ${ }^{53}$

\footnotetext{
49 Vicent BAYDAL, Els orígens de la revolta de la Unió, ed. Publicacions de la Universitat de València, València, 2013, p. 61.

50 Ernest Belenguer, Vida i regnat de Pere el Cerimoniós, ed. Pagès, Lleida, 2015. Sobre la vida de Pedro el Ceremonioso también ver: Rafael TAsIs, Pere el Cerimoniós i els seus fills, ed. Vicens Vives, Barcelona, 1980.

51 Mario Lafuente y Santiago Simón, "El proceso contra el infante Fernando de Aragón, acusado de lesa majestad, en 1363", eHumanista/IVITRA 7 (2015), p.156.

52 José Vicente CABezuelo, "Resolución del conflicto entre Pedro IV y el Infante Fernando. Los acuerdos de Albarracín de 1357”, Anuario de Historia del derecho español, 83 (2013), pp. 762-764.

53 Ernest Belenguer, Vida i regnat ..., p. 162.
} 
Cuando, en 1359, se agravó la contienda y el Ceremonioso se vio forzado a marcharse a liberar Ibiza ${ }^{54}$, la delegación del poder real no podía hacerse en el Procurador General, su hermanastro, quien, a pesar de ser el primer magistrado de la Corona, había representado la lucha contra el gobierno del Ceremonioso en las décadas anteriores, tanto en contiendas interiores, como fue la Guerra de la Unión, como en exteriores, como era la Guerra contra Castilla. La posibilidad de delegar la totalidad del poder real en su hermanastro Fernando suponía o podía suponer para el soberano poner en riesgo su autoridad y legitimidad durante un conflicto bélico en el que ya se encontraba en clara inferioridad.

Esta circunstancia nos parece que fue determinante para la elección de Leonor de Sicilia como lugarteniente general en la Corona de Aragón aun siendo, a su vez, reina consorte. De hecho, consideramos que Leonor de Sicilia fue la primera reina lugarteniente en la historia de la Corona de Aragón, si bien la historiografía especializada había otorgado hasta el momento esta distinción a Blanca de Anjou y Teresa de Entença ${ }^{55}$. A nuestro parecer, no obstante, hay evidencias documentales suficientes como para determinar que Leonor de Sicilia fue la primera monarca consorte de la Corona en detentar el cargo, como vamos a ver a continuación.

En primer lugar, por las circunstancias de vida y relación que determinaron el reinado de Pedro y Leonor, como ya hemos sintetizado anteriormente. En segundo lugar, por la todavía primigenia y escasa evolución del sistema de la delegación y representación regia entre la magistratura de la Procuración y la designación de la Lugartenencia. Y, en tercer lugar, porque las evidencias cronológicas y documentales no solo no dan ningún respaldo a la posibilidad de que Blanca de Anjou o Teresa de Entença fueran en efecto lugartenientes de la Corona, sino que, por el contrario, parecen negarla.

\footnotetext{
54 José Vicente CABEZUelo, "La guerra en el mar... ", pp. 116-150.

55 En su primer trabajo sobre reginalidad en la Corona de Aragón, Theresa Earenfight hacía referencia a ocho reinas consortes que ejercieron como lugartenientes. Según la norteamericana, Blanca de Anjou, Teresa de Entença, Leonor de Sicilia, Sibila de Fortià, Mata de Armanyac, Violant de Bar, María de Luna; Margarita de Prades y, finalmente, María de Castilla; fueron designadas lugartenientes por sus esposos. Theresa Earenfight, "María of Castile, Ruler or Figurehead...", pp. 45-6, op. cit. 23. Años después, en su trabajo Theresa EARENFight, "Absent Kings: Queens as political partners in the Medieval Crown of Aragon", Queenship and Political Power in Medieval and Early Modern Spain, Theresa Earefight (Ed.), ed. Aldershot, 2005, pp. 32-52, retomó el listado, rectificándolo y presentado un total de siete reinas lugartenientes: Blanca de Anjou, Teresa Entença, Violant de Bar, María de Luna, Margarita de Prades, María de Castilla y Juana Enríquez. Esta hipótesis la mantuvo en su artículo Theresa Earenfight, "Without the Persona of the Prince: Kings, Queens and the Idea of Monarchy in Late Medieval Europe", Gender and History, 19 (2007), pp. 1-21. Del mismo modo que en uno de sus libros: Theresa Earenfight, The King's Other Body.., p. 41. Sin embargo, lo modificó en su obra más celebre: Theresa EAREnfight, Queenship in Medieval..., pp. 129 y 168. Las siete reinas lugartenientes habrían sido Blanca de Anjou, Teresa Entença, Leonor de Sicília, Violant de Bar, María de Luna, María de Castilla y Juana Enríquez, Este listado confeccionado por la hispanista se ha repetido en la historiografía especializada en reginalidad, apareciendo en la mayoría de obras que se han aproximado a la figura de la consorte en la península ibérica, pero también en Europa en general. Sin embargo, como mostramos a continuación se trata de una confusión en la interpretación de las fuentes cancillerescas originales.
} 


\subsection{El caso de Blanca de Anjou}

En los trabajos realizados por Theresa Earenfight se afirma que Blanca de Anjou ${ }^{56}$ fue la primera reina consorte que ejerció la Lugartenencia real en la Corona de Aragón ${ }^{57}$. La hispanista norteamericana atribuye unas fechas concretas durante las cuales la consorte habría desempañado el cargo de lugarteniente, concretamente en la primavera de 1310, entre abril y junio, por la ausencia del rey, quien estaría en la guerra de Almería ${ }^{58}$. Según la especialista, la documentación que daría apoyo a dicha teoría se encuentra en varios registros de Cancillería conservados en el Archivo de la Corona de Aragón y en las cartas reales de la reina conservadas en el citado archivo para dicho período ${ }^{59}$. Sin embargo, hay elementos en su teoría que no pueden ser contrastados con la documentación.

En primer lugar, tanto la cronología de la guerra de Almería, como el itinerario del monarca, son bien conocidos ${ }^{60}$. La guerra, o mejor dicho, el asedio de Almería ${ }^{61}$ fue una campaña militar orquestada entre los reyes de Castilla y Aragón para intentar conseguir capturar la ciudad ${ }^{62}$. La ofensiva se llevó acabo entre el verano de 1309 y febrero de 1310. Concretamente, el itinerario de Jaime II sitúa al rey en Almería entre el 14 de agosto de 1309 y el 30 de enero de 1310, llegando el día 2 de febrero a Alicante ${ }^{63}$. Por lo tanto, la cronología del ejercicio de la Lugartenencia y el motivo por el cual se

\footnotetext{
56 Blanca de Anjou era hija de Carlos II de Nápoles y María de Hungría. Su matrimonio se organizó con Jaime II en 1295 como parte del tratado de paz de Cefalú, firmado diez años antes, por le que se reconocía el gobierno de Jaime II de Sicilia a cambio de la liberación de Carlos de Anjou del cautiverio al que lo tenía sometido Roger de Lluria. La diferencia de edad entre ambos era de 16 años, lo que no impidió que juntos tuvieran 10 hijos en 15 años de matrimonio.

57 En su primer trabajo sitúa la Lugartenencia de Blanca de Anjou entre abril y mayo de 1310, por la supuesta ausencia del rey Jaime II con ocasión de la cruzada de Almería. Citando ACA, Cartas Reales, caja 31, documentos 3.871-3.890. Theresa Earenfight, "María of Castile, Ruler or Figurehead?...", pp. 45-6, op. cit. 23. Posteriormente, puntualizó las fuentes utilizadas, especificando para el caso de Blanca de Anjou, ACA, R.C, reg. 59-62 y ACA, RC, reg. 289 y 290. Además, apostilla su afirmación citando el trabajo de Roger Soblonier, "The Aragoneses Royal Family around 1300", Interest and Emotion: Essays on the Study of Family and Kinship, Hans Medick, D.W. Sabean (eds.), ed. Cambridge University Press, 1984, pp. 210-239. Ver: "Absent Kings..., pp. 32-52. Unos años después, en su obra más importante, Queenship in Medieval Europe, actualiza la lista definitivamente a siete reinas lugartenientes. Para el caso de Blanca de Anjou solo cita sus registros de Cancillería ACA, RC, reg. 289 y 290. Ver: Theresa EARENFIGHT, Queenship in Medieval..., pp. 129 y 168.

58 Hemos utilizado las fechas publicadas en su último trabajo: Theresa EAREnfight, Queenship in Medieval ..., p. 168.

59 ACA, Carta reales, caja 31, documentos 3871-3890. ACA, RC, reg. 59-62 y ACA, RC, reg. 289 y 290. Ver op. cit. 55.

60 Ya que existe un completísimo itinerario del monarca, disponible en la web de la Institución Fernando el Católico, Juan Manuel del Estal, Itinerario Jaime II de Aragón (1291-1327), ed. Institución Fernando el Católico, Diputación Provincial de Zaragoza, Zaragoza, 2009.

61 Vicent BAYDAL, La croada d'Almeria, 1309-1310: la host de Jaume II i el finançament de la campanya, Ed. Académica Española, Saarbrücken, 2012.

62 José Hinojosa Montalvo, Jaime II y el esplendor de la Corona de Aragón, Nerea, Donostia, 2006.

63 Juan Manuel del EsTaL, Itinerario Jaime II de Aragón (1291-1327), ed. Institución Fernando el Católico, Diputación Provincial de Zaragoza, Zaragoza, 2009, pp. 377-387.
} 
produjo no se sustentan con los datos que conocemos de la vida de Jaime II, ya que todo parece indicar que éste no estuvo en Almería en abril de 1310. Para disipar las dudas sobre la cronología y la ubicación de los monarcas entre los años 1309 y 1310 , hemos considerado oportuno trazar el itinerario de la reina Blanca, siguiendo las referencias topográficas indicadas en los dos registros de cronología que conservamos, que abarcan el período entre finales de 1308 a finales 1310, comparándolo con el itinerario confeccionado del rey Jaime $\mathrm{II}^{64}$ :

\begin{tabular}{lll}
\hline FECHA & LA REINA $^{65}$ & EL REY \\
\hline $28-12-1308$ & Zaragoza & Zaragoza \\
\hline $21-01-1309$ & Sariñena & Sariñena \\
\hline $01-02-1309$ & Monzón & Monzón \\
\hline $10-02-1309$ & Lleida & Lleida \\
\hline $13-02-1309$ & Monasterio de Poblet & No consta \\
\hline $22-02-1309$ & Barcelona & Barcelona \\
\hline $15-07-1309$ & Valencia & Valencia \\
\hline $09-09-1309$ & Asedio Almería & Asedio Almería \\
\hline $21-02-1310$ & Valencia & Valencia \\
\hline $01-05-1310$ & Teruel & Teruel \\
\hline $21-05-1310$ & Cella & Cella \\
\hline $23-05-1310$ & Teruel & Teruel \\
\hline $04-07-1310$ & Daroca & Daroca \\
\hline $08-07-1310$ & Cariñena & Cariñena \\
\hline $10-07-1310$ & Zaragoza & Zaragoza \\
\hline $25-07-1310$ & Lleida & Lleida \\
\hline $02-09-1310$ & Monasterio de Poblet & Montblanc (A 10 km) \\
\hline $16-09-1310$ & Tarragona & Tarragona \\
\hline Cun & Barcelona & Barcelona \\
\hline
\end{tabular}

Cuadro de elaboración propia del itinerario reina Blanca y rey Jaime II de Aragón.

64 El cuadro se ha confeccionado tomando como referencia el día en que se documenta un cambio de ubicación de la reina y se compara con la presencia en el rey o no en esa villa.

65 Itinerario confeccionado a través de las referencias espaciales indicadas en la datación de las diferentes entradas registradas en la Cancillería de la reina, concretamente: ACA, RC, reg. 289 y 290. 
Con la comparativa de los itinerarios regios podemos ver como la reina y el rey no estuvieron separados (o, si lo estuvieron, fue simplemente por unos pocos días) durante un período de casi dos años ${ }^{66}$. Del mismo modo, confirmamos que no se produjo ninguna ausencia del rey en la primavera de 1310, sino que ésta se produjo en 1309, pero la reina lo acompañaba en su viaje, por lo que hemos de considerar inválida la hipótesis de la permanencia de Blanca en la Corona como su lugarteniente por el asedio de Almería o cualquier otra ausencia del monarca.

Además, la otra posibilidad, la enfermedad del monarca, tampoco se justifica puesto que se puede atestiguar la continuada actuación gubernativa del mismo durante el período de dos años que abarca el itinerario antes mostrado. En esa misma línea, debemos considerar que el infante Jaime, primogénito de Jaime II y la reina Blanca, era entonces el Procurador General de la Corona de Aragón ${ }^{67}$, por lo que, si hubiese sido necesaria la designación de un lugarteniente dentro de la familia real, la opción más inmediata hubiese sido el mismo infante y no la reina Blanca ${ }^{68}$. Del mismo modo, tampoco encontramos ninguna prueba documental que confirme su ejercicio como lugarteniente.

La documentación referida para justificar esta Lugartenencia son seis registros de Cancillería y veinte cartas reales ${ }^{69}$. Después de la lectura y análisis de las mismas, en ningún caso encontramos ni una intitulación como lugarteniente, ni fórmulas cancillerescas idénticas o semejantes en significado al "del qual tenim loch" que encontramos en la documentación de Leonor de Sicilia ${ }^{70}$. Tampoco encontramos en esa documentación actuaciones o atribuciones propias del ejercicio gubernamental desarrollado por el monarca ni semejante a lo que realizaría, más adelante, Leonor de Sicilia. En el caso de las cartas reales, estas sí pertenecen al período de reinado de Jaime II y concretamente al período en el que la norteamericana había establecido la Lugartenencia de la reina Blanca, aunque ninguna de las cartas contenga información que demuestre esta hipótesis. Para esclarecer el contenido de estas cartas, hemos incluido a continuación un breve resumen de las mismas junto con las fechas de expedición de aquellas realizadas en la Cancillería de la Corona de Aragón.

\footnotetext{
66 Con anterioridad, en el período 1306 a 1309 que es el que abarca la documentación de Cancillería conservada de la reina Blanca y para el que también hemos confeccionado el itinerario de la reina, tampoco se documenta que estuvieran separados, más que una cuestión de días.

67 José Vicente Cabezuelo, Poder público..., pp. 406-408.

68 A diferencia de 1359, como hemos visto, cuando el rey Pedro el Ceremonioso se encontraba en una posición muy complicada para delegar su autoridad en otro miembro de la familia real que no fuera su esposa y madre de sus herederos, en este caso no había ninguna circunstancia que pudiera poner en una situación delicada al rey por la elección de su sucesor para el cargo.

69 Los seis registros de Cancillería serían los siguientes: ACA, RC, reg. 289-290; ACA, RC, reg. 59-62. En cuanto a las cartas reales nos referimos a: ACA, Cartas Reales, Jaime II, documentos 3.871-3.890.

70 Más aún, puesto que los registros de Cancillería ACA, RC, reg. 59-62, no corresponden ni a la reina Blanca, ni al rey Jaime II ni a su hijo Alfonso. Estos pertenecen al infante Alfonso, hijo de Pedro el Grande, siendo lugarteniente de la Corona en 1282-1283.
} 
ACA, RC, Carta Real, 3.871. Jaime II a los consellers de Barcelona.

ACA, RC, Carta Real, 3.872. Jaime II sobre asuntos en Castilla.

ACA, RC, Carta Real, 3.873. Jaime II al justicia de Teruel sobre un pago pendiente. Teruel, 1 de mayo de 1310 .

ACA, RC, Carta Real, 3.874. Concesión de Jaime II a una vecina de Teruel enviada al justicia de esta villa. Teruel, (no conservado) abril de 1310.

ACA, RC, Carta Real, 3.875. Jaime II a su "tinent del segell". Teruel, 5 de abril de 1310.

ACA, RC, Carta Real, 3.876. Carta de Juan, hijo del infante don Manuel a la reina Blanca de Anjou sobre la casa de la señora Isabel. Teruel, 2 de mayo de 1310.

ACA, RC, Carta Real, 3.877. Carta de Juan, hijo del infante don Manuel al rey Jaime II sobre la casa de la señora Isabel. Teruel, 2 de mayo de 1310.

ACA, RC, Carta Real, 3.878. Blanca de Anjou a su tesorero sobre la donación de una mula a Francesc Casala. Y dice así: Dona Blancha, por la gracia de Dios, reyna de Aragón. Al fiel trasorero nostro en (sobreescrito) Romero Giralt, salut e gracia. Mandamos vos que de des an Francresc Casala la mula vostra... Castillo de Santa Croce (Albarracín, Teruel), 9 de mayo de 1310.

ACA, RC, Carta Real, 3.879. Jaime II al baile de las montañas de Prades. Teruel, 11 de mayo de 1310.

ACA, RC, Carta Real, 3.880. Blanca de Anjou a Domingo de Granyana, lugarteniente de su tesorero, Ramon Giralt, sobre el pago de 3.000 libras de oro de Barcelona. Y dice así: Blancha, Dei gratia etc. Fideli suo Dominico de Granyana, tenenti locum Romum Gerald. Terol, 11 de mayo de 1310.

ACA, RC, Carta Real, 3881. Jaime II al justicia de Teruel sobre el caso de Domingo Ferrández, vecino de Teruel. Teruel, 14 de mayo de 1310.

ACA, RC, Carta Real, 3.882. Jaime II al baile de Teruel. Teruel, 15 de mayo de 1310.

ACA, RC, Carta Real, 3.883. Jaime II al justicia de Daroca. Teruel, 20 de mayo de 1310.

ACA, RC, Carta Real, 3.884. Jaime II a la villa de Teruel. Cella, 24 de mayo de 1310.

ACA, RC, Carta Real, 3.885. Concesión de Jaime II a la villa de Teruel. Cella, 24 de mayo de 1310.

ACA, RC, Carta Real, 3.886. Documento firmado entre el rey de Granada y el rey Fernando de Castilla con las condiciones del vasallaje jurado por el rey de Granada al rey de Castilla.

ACA, RC, Carta Real, 3.887. Carta del rey de Granada informando que ha jurado vasallaje al rey Fernando de Castilla.

ACA, RC, Carta Real, 3.888. Jaime II al justicia de Calatayud. Teruel, 29 de mayo de 1310.

ACA, RC, Carta Real, 3.889. Carta recibida por Jaime II sobre asuntos de Castilla.

ACA, RC, Carta Real, 3.890. Carta del rey de Castilla.

Cuadro de elaboración propia de las cartas reales del período abril y mayo de 1310 conservadas en el Archivo de la Corona de Aragón.

Como vemos, solo hay tres cartas vinculadas con la reina Blanca, dos enviadas por ella y una tercera recibida por ella. Las dos primeras fueron enviadas por la reina Blanca a su tesorero, Ramon Giralt, o al lugarteniente de su tesorero, Domingo Granyana. Pero en ningún caso se documenta ninguna referencia a la reina como lugarteniente ni tampoco vemos ninguna actuación por su parte como tal. 
Y es que, gracias al hecho de haberse fijado un margen cronológico tan exacto para su Lugartenencia, de abril a junio, hemos podido detectar la pequeña confusión que creemos que puede haber dado pie a la incorrecta atribución a Blanca de Anjou del ejercicio como lugarteniente. En el registro de Cancillería 28971, en los folios 143 recto y 145 vuelto, encontramos la documentación expedida por la Cancillería de la reina en el período de abril a junio de 1310. Precisamente en las entradas de los dos documentos que reflejan los folios citados encontramos la expresión "locum tenenti" al inicio de la oración, justo después de la intitulación, en el caso del folio 143 recto sobrescrito en la parte de arriba de la primera línea ${ }^{72}$. En el folio 145 vuelto, encontramos como la reina se refiere al vicario de Tortosa y seguido por "vel eius locum tenenti", ${ }^{73}$ que traducido sería "o a su lugarteniente', puesto que el "vel" tiene un claro valor disyuntivo en la oración ${ }^{74}$. Es decir, podemos ver que en ambos casos la mención al locum tenens no hace referencia a la reina como lugarteniente del rey, sino al lugarteniente del receptor de la carta. Lo mismo ocurre en el caso de las Cartas Reales anteriormente expuestas. En la única misiva en la que aparece "tenenti locum" es en la carta 3880 y esta expresión también alude al destinatario de la carta. Se evidencia así lo que a nuestros ojos ha sido una pequeña confusión en la interpretación de la fuente original del texto, en latín, aceptando como de la reina la referencia al lugarteniente propio del receptor de la misiva.

\subsection{El caso de Teresa de Entença, una infanta entendida como reina}

Por lo que refiere a Teresa de Entença, también son de índole cronológica y documental las razones que nos llevan a pensar que tampoco pudo haber ostentado la Lugartenencia real en la Corona de Aragón ${ }^{75}$. En esta ocasión, la primera confusión ha sido otorgarle la dignidad reginal cuando nunca la ostentó. Teresa de Entença contrajo matrimonio con

\footnotetext{
71 ACA, RC, reg. 289.

72 "Blancha, Dei Gratia, etc. Fideli suo Bernardo Despelleucis baiulo Regni Valencie Generali vel eius locum tenenti" ACA, RC, reg. 289, fol. 143r.

73 "Dilecto suo Bernardo de Podiatis, viccario Dertuse, vel eius locum tenenti".

74 En el primer caso sería: "Blanca, por la gracia de Dios, etc., al fiel Bernardo Desplugues, baile general de Valencia o a su lugarteniente". En el segundo: "Al amado Bernardo Pujades, veguer de Tortosa, o a su lugarteniente".

75 Por lo que respeta a Teresa de Entença, la historiadora norteamericana Theresa Earenfight limita su Lugartenencia a los últimos meses de su vida, en 1327, y cita los registros conservados para ésta: ACA, RC, reg. 426 y 427. Theresa EARENFight, "María of Castile, Ruler or Figurehead...", pp. 45-6, op. cit. 23. Años después, retomó el listado y para el caso de Teresa de Entença nuevamente afirmó su Lugartenencia mediante los registros 426 y 427. Ver: Theresa EARENFight, "Absent Kings...", pp. 32-52. Al igual que en el caso de Blanca de Anjou, esta hipótesis la mantuvo en su artículo Theresa EARENFIGHT, "Without the Persona of the Prince...", pp. 1-21. Del mismo modo que en su libro: Theresa EArenfight, The King's Other Body..., p.41. Y así se ha mantenido hasta su obra Theresa EARENFIGHT, Queenship in medieval Europe. Sin embargo, en esta obra la autora se da cuenta que en el caso de Teresa de Entença debe tratarse de una confusión y especifica lo siguiente: "A generation later, Teresa d'Entença certainly governed for her husband, Alfonso IV, in 1327, and perhaps earlier, but the documentation for her reign is unclear. There is no official document naming her lieutenant, and she may have been more a regent than a lieutenant". Es decir, sin determinar la fecha, considera que Teresa ejercería un tipo de regencia, aunque no especifica el motivo por el cual puntualiza y diferencia entre regencia y Lugartenencia. Theresa EARENFIGHT, Queenship in Medieval Europe, ed. Palgrave Macmillan, 2012, p.168.
} 
Alfonso de Aragón, hijo y heredero de Jaime II, en 1319 y murió el 28 de octubre de 1327, mientras que su suegro, el rey Jaime II moriría el 2 de noviembre de 1327, por lo que Teresa fue la esposa de Alfonso cuando éste era infante y no rey de la Corona de Aragón $^{76}$. Consecuentemente, si entonces el rey, Jaime II, hubiera necesitado designar un lugarteniente, el escogido en primer lugar según la lógica hubiera sido su hijo, el infante Alfonso, y no su esposa, la reina Elisenda de Moncada, aun menos la esposa del infante, Teresa de Entença. De hecho, esto mismo es lo que en efecto hizo el monarca, que confió los asuntos de gobierno a su hijo Alfonso, quien durante todo el año 1327 ejerció como Procurador General la magistratura oficial más elevada de la administración monárquica ${ }^{77}$. Durante el año 1327, los infantes Alfonso de Aragón y Teresa de Entença no se separaron en ningún momento, ya que hemos confeccionado el itinerario de ambos para atestiguar si en algún momento Alfonso y Teresa pudieron estar separados, única circunstancia que hubiera podido requerir que la infanta tomara las atribuciones de su esposo ${ }^{78}$.

\begin{tabular}{lllll}
\hline FECHA & Lugar Infanta & $\begin{array}{l}\text { Referencia } \\
\text { documental }\end{array}$ & Lugar Infante & $\begin{array}{l}\text { Referencia } \\
\text { documental }\end{array}$ \\
\hline $04-02-1327$ & Daroca & R. 427 f. 24r & Daroca & R. 403, f. 9r \\
\hline 25-03-1327 & Calatayud & R. 427 f. 25v & Calatayud & R. 381, f. 3r \\
\hline $02-04-1327$ & Zaragoza & R.427, f. 26v & Zaragoza & R. 381, f. 14r \\
\hline $06-05-1327$ & Montalbán & R. 427, f. 25r & Montalbán & R. 381, f. 85v \\
\hline 28-05-1327 & Barcelona & R. 427, f. 27r & Barcelona & R.403, f. 62v \\
\hline 31-06-1327 & Beceite & R. 427, f. 29v & Beceite & R.414, f. 3r \\
\hline 28-07-1327 & Morella & R. 427, f. 30r & Morella & R. 381, f. 228v \\
\hline 22-09-1327 & Zaragoza & R.427, f. 33r & Zaragoza & R. 414, f. 14v $\mathrm{v}^{81}$ \\
\hline Cuadr0
\end{tabular}

Cuadro de elaboración propia del itinerario Teresa de Entenza y el infante Alfonso de Aragón en $1327^{82}$

\footnotetext{
$\overline{76}$ José Vicente Cabezuelo, Poder público ..., pp. 333.

77 José Vicente Cabezuelo, Poder público ..., pp. 408-446. También podemos encontrar en sus registros documentales la intitulación como procurador general. Por ejemplo dentro de esta cronología: "De Nós, Infant don Alfonso, del muyt alto Senyor Rey de Aragón, primogénito, general procurador e comte d'Urgell" ACA, RC, reg. 414, fol. 11r, segunda numeración.

78 Como en el caso anterior, hemos confeccionado el itinerario identificando dónde se encontraba la infanta en un determinado momento y comparándolo con la ubicación del infante Alfonso. Se ha repetido el mismo ejercicio cuando encontramos un cambio de ubicación en la infanta. Con todo, hemos podido ver que ambos itinerarios son prácticamente idénticos y que solo se separarían durante unos pocos días.

79 (segunda numeración).

80 (segunda numeración).

81 (segunda numeración).

82 Para la confección del itinerario hemos empleado las fechas en el que se documenta a la infanta por primera vez en una nueva villa a través del registro 427 de Cancillería y hemos buscado en la cancillería del infante si se le puede encontrar en ese mismo lugar en esa misma fecha.
} 
Como muestra el cuadro, siempre que la infanta estuvo en algún lugar o villa diferente, el infante se encontraba con ella, por lo que no podemos hablar de ninguna ausencia por parte del infante para justificar la Lugartenencia de la infanta.

Del mismo modo no encontramos ninguna referencia ni formulismo cancilleresco que verifique que la infanta actuó como lugarteniente real. De hecho, parece haberse producido el mismo error de interpretación que ya hemos detectado en el caso de Blanca de Anjou. Así, vemos que en el mes de octubre ${ }^{83}$ aparece otra vez la misma fórmula "vel eius locum tenenti" ${ }^{84}$, que consideramos que nuevamente ha de interpretarse como referida al locum tenens del receptor de la misiva y no a la propia reina, que no desempeñó este cargo.

Por todo lo dicho, queda patente que Leonor de Sicilia, en 1359, fue la primera reina de la Corona de Aragón que ejerció de lugarteniente, es decir que, teniendo el lugar del rey, asumió la gobernanza delegada de la Corona, en este caso, durante la Guerra de los Dos Pedros y por motivo de la ausencia del rey y las circunstancias ya descritas.

La reina Leonor de Sicilia fue nombrada lugarteniente real de la Corona en seis ocasiones entre los años 1359 y 1375 . Después del primer ejercicio del cargo, se prescindiría, en la documentación cancilleresca de la monarca, de la fórmula " $\mathrm{del}$ qual tenim loch" y su condición de lugarteniente se manifestaría con la inclusión, después de su nombre, de la fórmula "lochtinent del Senyor Rey" o sus derivados ("generalisque locum tenens serenissimum Domini regis"), como puede verse en el siguiente texto, en el que se hace referencia al nombramiento expedido en 1364 por el Ceremonioso en favor de su esposa:

"In nomine Domini. Noverint universi quod nos, Alianora, Dei gratia regina Aragonum, Valencie, et cetera, generalisque locum tenens serenissimum Domini regis viri nostri carissimi et etiam procuratrix ab eo ad hec et alia cum libera et generali administracione constituta cum publico instrumento, acto Cesaraguste, in palacio archiepiscopi, XXII ${ }^{\circ}$ die januarii, anno presenti, sigillo regio appendito comunito, clauso per Petrum Vitalis, dicti domini regis scriptore eiusque auctoritate notarium publicum per totam terram et dominacionem suam." $" 85$

\footnotetext{
83 Theresa Earenfight refiere que se trataría en los últimos meses de su vida: Theresa EARENFIGHT, "María of Castile, Ruler or Figurehead..., pp. 45-6, op. cit. 23. Ver en nota 61.

84 Infantissa etc Dilecto nostro Baiulo Balaguarii vel eius locum tenenti [...] Cessarauguste, $X^{o} \mathrm{kalendas}$ octobre anno domini M CCC XX septimo. ACA, RC, reg. 427, fol. 33r ( $1^{\mathrm{a}}$ numeración).

85 ACA, RC, reg. 995, fols. 113r -116r. Agradezco a Alberto Reche por ponerme en la pista de esta referencia que él mismo cita en: Alberto Reche, «Noverint universi quod ego, Guillelmus Morey...”: Un acercamiento biográfico a la relación entre élites urbanas, ambientes reales y guerra marítima a mediados del siglo XIV, Universitat Autònoma de Barcelona, 2015. Tesis doctoral, pp. 577-578.
} 
Si bien, como acabamos de ver, Leonor de Sicilia fue la primera reina lugarteniente en la Corona de Aragón, pero no la única. Posteriormente, ostentaron también el cargo Violante de Bar, esposa de Juan I; María de Luna, esposa de Martín el Humano; María de Castilla, durante la larga ausencia de Alfonso el Magnánimo; Juana Enríquez, con motivo de la guerra civil catalana y, finalmente, Germana de Foix, esposa de Fernando el Católico. Así, incluyendo a Leonor de Sicilia, un total de seis reinas de la Corona de Aragón ejercieron en la Edad Media el principal cargo de delegación del poder real por las necesidades de gestión gubernativa de la monarquía causadas por las ausencias o enfermedades de los monarcas. Además hubo otra mujer que sin ser reina consorte ejerció la Lugartenencia General, la infanta Juana de Aragón en 1475, hija de Juan II y Juana Enríquez, quien posteriormente se convertiría en reina de Nápoles por su matrimonio con Fernando I de Nápoles. Así, con la infanta Juana completaríamos la lista de las siete lugartenientes femeninas de la Corona de Aragón.

\section{Conclusiones}

Como muchos otros cambios en la gestión monárquica de la Corona de Aragón, la vinculación de la reina consorte con la Lugartenencia no llegaría hasta el reinado de Pedro IV de Aragón. En ese tiempo, Pedro el Ceremonioso y su consorte, Leonor de Sicilia, formalizarían públicamente la relación de colaboración gubernativa que unía a los monarcas, siendo su designación como lugarteniente la manifestación de esta vinculación política de los dos cónyuges y de la posición que la consorte estaba adquiriendo dentro de la monarquía.

Esta designación femenina fue un hecho sin precedentes y que quizás no se hubiera producido sin la urgencia que supuso la guerra de los Dos Pedros. La Guerra aparece como un acelerador de las reformas administrativas en la Corona de Aragón a mediados del siglo XIV, impulsando no solo la Lugartenencia femenina sino también reformas en la fiscalidad y la representatividad de los reinos ante el rey, como las Diputaciones de General. Esta coyuntura bélica, junto con las características familiares y personales del reinado de Pedro IV impulsaron una designación sin precedentes, formalizando el papel de la reina en la gobernanza de la Corona.

En este primer ejercicio de la Lugartenencia se observan las bases conceptuales propias de la designación. La reina, como segunda de la monarquía y colaboradora del rey, asumía su lugar en la cúspide política y gubernamental por delante del resto de oficiales, disponiendo de todas las capacidades propias del ejercicio de poder monárquico en su persona. Se exhibe y se aumenta la autoridad de la consorte convirtiendo su poder, obtenido de la relación con el monarca, en un poder delegado para el ejercicio gubernativo durante la ausencia de su esposo.

Con esta designación la reina Leonor, pero también sus sucesoras en el cargo, cumplirían con el encargo dejado por el rey, haciendo todo lo necesario para materializar los objetivos de ambos. La vinculación de la reina a la Lugartenencia tiene reminiscencias 
a la vinculación del primogénito a la Procuración general. A su vez, esta elección encaja con la evolución dada en la imagen pública y exhibida de la monarquía y la Familia Real, en el que la reina tendrá un papel remarcable en la actividad política.

Fecha de recepción: 22 de febrero de 2017

Fecha de aceptación: 2 de mayo de 2017 